\title{
Patterns, magnitude, and controlling factors of hydraulic redistribution of soil water by Tamarix ramosissima roots
}

\author{
TengFei $\mathrm{YU}^{1,2}$, Qi FENG ${ }^{2,3^{*}}$, JianHua $\mathrm{SI}^{2,3}$, HaiYang $\mathrm{XI}^{2,3}$, Wei $\mathrm{LI}^{2}$ \\ ${ }^{1}$ Research School of Arid Environment and Climate Change, Lanzhou University, Lanzhou 730000, China; \\ ${ }^{2}$ Cold and Arid Regions Environmental and Engineering Research Institute, Chinese Academy of Sciences, Lanzhou 730000, China; \\ ${ }^{3}$ Gansu Hydrology and Water Resources Engineering Research Center, Lanzhou 730000, China
}

\begin{abstract}
Tamarix spp. (Saltcedar) is a facultative phreatophyte that can tolerate drought when groundwater is not accessed. In addition to deep water uptake, hydraulic redistribution (HR) is another factor contributing to the drought tolerance of Tamarix spp. In this study, data on soil volumetric moisture content $(\theta)$, lateral root sap flow, and relevant climate variables were used to investigate the patterns, magnitude, and controlling factors of HR of soil water by roots of Tamarix ramosissima Ledeb. in an extremely arid land in Northwest China. Results showed evident diurnal fluctuations in $\theta$ at the depths of 30 and $50 \mathrm{~cm}$, indicating "hydraulic lift" (HL). $\theta$ increased remarkably at 10 and $140 \mathrm{~cm}$ but decreased at 30 and $50 \mathrm{~cm}$ and slightly changed at $80 \mathrm{~cm}$ after rainfall, suggesting a possible "hydraulic descent" (HD). However, no direct evidence was observed in the negative flow of lateral roots, supporting $\mathrm{HR}$ (including HL and HD) of $T$. ramosissima. The HR pathway unlikely occurred via lateral roots; instead, HR possibly occurred through adventitious roots with a diameter of $2-5 \mathrm{~mm}$ and a length of $60-100 \mathrm{~cm}$. HR at depths of $20-60 \mathrm{~cm}$ ranged from $0.01-1.77 \mathrm{~mm} / \mathrm{d}$ with an average of $0.43 \mathrm{~mm} / \mathrm{d}$, which accounted for an average of $22 \%$ of the estimated seasonal total water depletion at $0-160 \mathrm{~cm}$ during the growing season. The climate factors, particularly vapor pressure deficit and soil water potential gradient, accounted for at least $33 \%$ and $45 \%$ of $\mathrm{HR}$ variations with depths and years, respectively. In summary, T. ramosissima can be added to the wide list of existing species involved in HR. High levels of HR may represent a considerable fraction of daily soil water depletion and substantially improve plant water status. HR could vary tremendously in terms of years and depths, and this variation could be attributed to climate factors and soil water potential gradient.
\end{abstract}

Keywords: drought tolerance; phreatophyte; hydraulic redistribution; root sap flow; Tamarix ramosissima

Citation: TengFei YU, Qi FENG, JianHua SI, HaiYang XI, Wei LI. 2013. Patterns, magnitude, and controlling factors of hydraulic redistribution of soil water by Tamarix ramosissima roots. Journal of Arid Land, 5(3): 396-407.

In addition to morphological and stomatal adjustments of above-ground parts of plants, another strategy that desert plants use to tolerate drought involves the production of roots that have access to deep groundwater (Lambers et al., 2008). Thus, deep water uptake is a potential mechanism of desert phreatophytes to adapt to drought (Anderson, 1982; Busch et al., 1992; Sala et al., 1996; Gries et al., 2003). However, deep water uptake may be limited because of low densities of fine roots in deep soil layers under high evaporative demand considering that the majority of fine roots $(\leq 2$ $\mathrm{mm}$ in diameter) are present near soil surfaces (the upper $30 \mathrm{~cm}$ ) in desert ecosystems (Jackson et al., 1996; Jackson et al., 1997). To tolerate drought during dry seasons, desert phreatophytes also undergo hydraulic redistribution (HR) of soil water, a process in

*Corresponding author: Qi FENG (E-mail: qifeng@ns.lzb.ac.cn) 
which water passively moves from moist to dry regions in soil via root systems (Richards and Caldwell, 1987; Caldwell and Richards, 1989; Burgess et al., 1998; Hultine et al., 2003; Ludwig et al., 2003).

HR in arid and semi-arid ecosystems has been welldocumented (Richards and Caldwell, 1987; Caldwell and Richards, 1989; Dawson, 1993; Burgess et al., 1998; Hultine et al., 2003; Hultine et al., 2004; Oliveira et al., 2005; Zou et al., 2005). However, only a few studies have focused on HR of desert phreatophytes in arid regions in Central Asia, particularly HR of facultative phreatophytes such as Tamarix spp. (saltcedar), probably because saltcedar can obtain water supply directly from deeper groundwater and tolerate drought (Anderson, 1982; Sala et al., 1996). However, other studies have revealed that T. ramosissima can also extract water from unsaturated soil layers, providing a significant competitive advantage compared with native obligate phreatophytes such as Populus spp. and Salix spp., which obtain water solely from water tables (Busch et al., 1992). Phreatophyte roots also absorb mineral nutrients from upper soil layers when surface soil dries over time (Prieto et al., 2012); root systems may function as conduits to redistribute water potentially from moist to dry soil layers (Burgess et al., 1998).

T. ramosissima is a native phreatophyte in Central Asia but an invasive shrub along riverbanks in southwestern United States (Nagler et al., 2003). Increased concerns regarding the future of native species in Northwest China have focused on water source and water consumption as well as the effects on biodiversity and hydrological resources of riparian zones (Feng and Cheng, 1998; Liu et al., 2010). Zhou et al. (2004) reported that the vertical distribution of soil water content is associated with root density, but the authors did not provide a reasonable explanation for this finding. We previously also observed increases in water content of upper soil layers in these regions at nighttime during dry periods (Xi et al., 2008). Thus, we hypothesized that $T$. ramosissima may undergo HR. In the present study, the previous conjecture that $T$. ramosissima can redistribute water to cope with drought was investigated. Specifically, we determine the patterns, magnitude, and controlling factors of HR of soil water by $T$. ramosissima roots in the extremely arid land of Northwest China.

\section{Materials and methods}

\subsection{Study area and plant species}

The study was performed at the Alxa Desert Eco-hydrology Experimental Research Station (abbreviated as Alxa Station; $42^{\circ} 01^{\prime} \mathrm{N}, 100^{\circ} 21^{\prime} \mathrm{E}$, $883.54 \mathrm{~m}$ asl), Chinese Academy of Sciences, which is approximately $800 \mathrm{~m}$ to the west of the Heihe River in Northwest China. The climate in this area is arid with a mean annual precipitation of $37.36 \mathrm{~mm}$, of which $>75 \%$ occurs from June to August. The mean annual evaporation is $3,390.26 \mathrm{~mm}$, approximately 90 times the precipitation. The mean temperatures in July and January are $26.95^{\circ} \mathrm{C}$ and $-11.68^{\circ} \mathrm{C}$, respectively, as recorded by the Ejin Weather Station from 1959 to 2011. Given that rain and heat are greatest during the same period, most rainwater is depleted by evaporation before rain infiltrates into deep soil layers; therefore, the effect of rainfall on soil moisture balance is weak. In addition to rainfall, groundwater recharged by the runoff in Heihe River is the main water source to retain the survival of local residents and ecosystems.

The area has sandy loam soil at a depth of $20 \mathrm{~cm}$, with a sulfate salt crust on the soil surface. Silt loam is found at the depth of $20-160 \mathrm{~cm}$ with a distinct sand soil layer between 82 and $124 \mathrm{~cm}$, according to the soil texture classification standard of US Department of Agriculture (USDA) (Table 1). The parent soil material is fluvial sediment with gray-brown desert soil. The community is dominated by $T$. ramosissima, which has a high density of $42 \mathrm{stem} / \mathrm{hm}^{2}$, an average height of $1.87 \mathrm{~m}$, a coverage of $52 \%$, and accounts for approximately $75 \%$ of the total basal area. The understorey is composed of shallow-root grasses, predominantly Sophora alopecuroides L., Karelinia caspica (Pall.) Less, and Achnatherum splendens (Trin.) Nevski. We selected two individual T. ramosissima plants to determine the sap flow of branches and roots, and a fence of $30 \mathrm{~m} \times 30 \mathrm{~m}$ was constructed around the plants to keep animals out of the study area. 
Table 1 Soil bulk density $\left(\rho_{b}\right)$, texture, and fitting parameters of soil water retention curves

\begin{tabular}{ccccccccc}
\hline $\begin{array}{c}\text { Depth } \\
(\mathrm{cm})\end{array}$ & $\begin{array}{c}\rho_{\mathrm{b}} \\
\left(\mathrm{g} / \mathrm{cm}^{3}\right)\end{array}$ & $\begin{array}{c}\text { Sand } \\
(\%)\end{array}$ & $\begin{array}{c}\text { Silt } \\
(\%)\end{array}$ & $\begin{array}{c}\text { Clay } \\
(\%)\end{array}$ & $\begin{array}{c}\theta_{r} \\
\left(\mathrm{~cm}^{3} / \mathrm{cm}^{3}\right)\end{array}$ & $\begin{array}{c}\theta_{s} \\
\left(\mathrm{~cm}^{3} / \mathrm{cm}^{3}\right)\end{array}$ & $\begin{array}{c}\alpha \\
\left(1 / \mathrm{cm}^{3}\right)\end{array}$ & $\begin{array}{c}K \mathrm{~s} \\
\left(\mathrm{~cm}^{2} \mathrm{~h}\right)\end{array}$ \\
\hline $0-7$ & 1.05 & 46.74 & 47.71 & 5.56 & 0.0416 & 0.4357 & 0.0069 & 1.5767 \\
$7-20$ & 1.43 & 49.17 & 43.86 & 6.97 & 0.0357 & 0.3593 & 0.0147 & 1.4728 \\
$20-47$ & 1.41 & 42.13 & 51.54 & 6.33 & 0.0365 & 0.3567 & 0.0100 & 1.5291 \\
$47-82$ & 1.28 & 28.45 & 63.86 & 7.69 & 0.0475 & 0.3972 & 0.0049 & 1.6972 \\
$82-124$ & 1.47 & 99.00 & 0.86 & 0.14 & 0.0540 & 0.3937 & 0.0311 & 4.4586 \\
$124-160$ & 1.54 & 25.37 & 70.80 & 3.83 & 0.0372 & 0.3470 & 0.0086 & 1.5643 \\
\hline
\end{tabular}

Note: $\theta_{r}$ and $\theta_{s}$ are residual and saturated soil water content, respectively; $\alpha$ and $n$ are Van Genuchten (1980) model parameters; and $K \mathrm{~s}$ is the saturated soil hydraulic conductivity.

\subsection{Sap flow measurement}

We used the heat ratio method (HRM; ICT, Armidale, $\mathrm{AU})$ to determine sap flow continuously in the branches and roots of the studied species. HRM (Burgess et al., 2001) was used to determine the increase in temperature after a heat pulse was observed at two symmetrical points. We inserted one heater and a pair of copper-constantan thermocouples radially into the xylem tissue of the major lateral roots and branches of the plants. Each thermocouple had two junctions to measure sap velocity in the xylem tissue at the two depths of 7.5 and $22.5 \mathrm{~mm}$ from the tip of the needle. A metal guide (with three holes carefully drilled on a parallel line, spaced $5 \mathrm{~mm}$ apart) was used to help drill holes and minimize probe misalignment during insertion. The heater was set up to send a pulse every $30 \mathrm{~min}$, and temperature ratios were recorded continuously by using a data logger (CR10x; Campbell Inc., Logan, UT, USA). The heat pulse velocity $\left(V_{h}\right)$ was calculated according to Burgess et al. (2001) as follows:

$$
V_{h}=\frac{k}{x} \ln \left(\frac{v_{1}}{v_{2}}\right) \times 3600 .
$$

Where $k$ is the thermal diffusivity of the fresh wood; $x$ is the distance between the heater and the thermocouples (fixed value of $0.5 \mathrm{~cm}$ in our study); and $v_{1}$ and $v_{2}$ are the differences between the initial temperature at the two thermocouples (downstream and upstream flow in relation to the heater, respectively) and the temperature measured after a heat pulse was generated. $k$ was initially fixed at $2.5 \times 10^{3} \mathrm{~cm}^{2} / \mathrm{s}$, but this value was adjusted after we determined the thermal properties of wood. All of these corrections for wound and misalignment of the probes were conducted according to Burgess et al. $(1998,2001)$. The sap flow velocity $\left(V_{\mathrm{s}}\right)$ was then calculated according to Burgess et al. (2001).

\subsection{Soil water content and metrological parame- ters}

We quantified soil volumetric moisture content $(\theta)$ and soil temperature $\left(T_{\mathrm{s}}\right)$ by using multisensor capacitance probes (EnviroSCAN; Sentek, Adelaide, AU) and soil temperature sensors (Campbell 109SS; Campbell Inc., USA), respectively. Each of these instruments contained five groups of probes that were embedded at different depths $(10,30,50,80$, and $140 \mathrm{~cm})$ and recorded at intervals of $10 \mathrm{~min}$ with a CR1000 data logger (Campbell Inc., USA). Each capacitance sensors was frequency-normalized by calibration against air and water in the laboratory to ensure the precision measurement. A default factory calibration equation based on combined soil types was used, and the field calibration equation (sandy loam of $10 \mathrm{~cm}$ : $y=1.6597 x^{0.1876}-2.2491, R^{2}=0.969$; and silt loam of 30 , 50, 80, and $140 \mathrm{~cm}: y=0.5512 x^{0.2582}-0.5272, R^{2}=0.987$, in which $y$ and $x$ are the scaled frequency and the volumetric soil water content in $\mathrm{mm}$, respectively) was then applied to determine absolute values of $\theta$ according to the Sentek calibration manual V2.0. Data at intervals of $30 \mathrm{~min}$ and their daily average were calculated to determine daytime and daily variations in $\theta$ and $T_{\mathrm{s}}$. Meteorological factors in the study area, including net radiation $\left(R_{n}\right)$, air temperature $\left(T_{a}\right)$, and relative humidity $(\mathrm{RH})$, were recorded using a CR3000 data logger (Campbell Inc., USA). $R_{\mathrm{n}}$ was measured by CNR4 (Kip and Zonen, the Netherlands), 
and $T_{a}$ and $\mathrm{RH}$ were measured using the relative humidity and temperature sensor (HMP45c; Campbell Inc. USA) at a height of $3 \mathrm{~m}$. Vapor pressure deficit (VPD) was calculated based on $T_{a}$ and $\mathrm{RH}$ according to Campbell and Norman (1998). The daily potential evapotranspiration (PET) was calculated by using Penman-Monteith equation based on FAO methodology (Allen et al., 1998). For forest canopy, the zero plane displacement height $(d)$ and the roughness length for momentum $\left(z_{0}\right)$ are approximated as 0.78 $h_{\mathrm{c}}$ and $0.075 h_{\mathrm{c}}$, respectively, where $h_{c}$ is the height of the plant canopy.

Large shifts in $T_{\mathrm{s}}$ can affect soil permittivity and response of capacitance sensors, thereby confounding the small fluctuations in $\theta$ attributable to HR. Thus, $\theta$ was adjusted when $T_{\mathrm{s}}$ differed from the laboratory calibration $T_{\mathrm{s}}\left(20^{\circ} \mathrm{C}\right) . T_{\mathrm{s}}$ adjustment was based on previous comprehensive calibrations in soil for a portable capacitance sensor operating at $60 \mathrm{MHz}$. This method used site-specific residual $\left(\theta_{\mathrm{r}}\right.$; for very dry soil) and saturated $\left(\theta_{\mathrm{s}}\right)$ soil water contents (Table 1$) . T_{\mathrm{s}}$ correction factors for $\theta\left(\Delta \theta_{T}\right)$ were individually calculated for each depth range based on a linear regression between $\Delta \theta_{T}$ and $\theta / \theta_{\mathrm{s}}$ and assumed $\Delta \theta_{T}$ (at $\left.\theta_{\mathrm{r}}\right)=0, \Delta \theta_{T}$ (at $\left.0.5 \theta_{\mathrm{s}}\right)=0.0014$, and $\Delta \theta_{T}\left(\right.$ at $\left.\theta_{\mathrm{s}}\right)=0.003$ (Warren et al., 2011).

The correction factors, $\Delta \theta_{T}$, were then applied to measure the soil moisture contents at each depth:

$$
\theta_{\text {corrected }}=\theta+\theta \times \Delta \theta_{T} \times\left(20^{\circ} \mathrm{C}-T_{\mathrm{s}}\right) .
$$

In addition, the gravimetrical soil moisture content was measured at 25 May, 31 July, and 6 September of 2012 , and was then multiplied by soil bulk density $\left(\rho_{\mathrm{b}}\right)$ to obtain soil volumetric moisture content $(\theta)$.

\subsection{Leaf and soil water potentials and root length density}

We collected leaf and soil samples at predawn and midday to monitor the seasonal variations in leaf and soil water potentials. The leaf and soil samples were duplicated at upper, middle, and lower layers and at 5-, 10-, and 20-cm depths, respectively. The samples were immediately taken to the laboratory to determine the leaf and soil water potentials by using a dew-point water potential meter (WP4C; Decagon Devices, USA). The groundwater table was measured via un- derground wells. These variables were measured at intervals of $5 \mathrm{~d}$. On 22 July 2012, the soil block samples $(10 \mathrm{~cm} \times 10 \mathrm{~cm} \times 10 \mathrm{~cm})$ were obtained from depths of 0-160 cm (three samples per layer) at intervals of $20 \mathrm{~cm}$. We brought the samples to the laboratory and washed the soil from the roots. We divided the roots into each layer in two-size classes based on root diameter: fine root $(\leq 2 \mathrm{~mm})$ and coarse root $(>2 \mathrm{~mm})$. All of the parts of living fine roots in each layer were digitally scanned using a flatbed scanner set at $600 \mathrm{dpi}$ and saved as TIF files. Root images were analyzed using image analysis software (WinRHIZO Pro 2008a, Regent Instruments Inc., Quebec, Canada). The root length density (RLD, $\mathrm{cm} / \mathrm{cm}^{3}$ ) of fine roots was determined from the total root length $(L)$ divided by the volume $(V)$ of the soil block.

Table 2 Environmental and stand characteristics of T. ramosissima during the growing season*

\begin{tabular}{ccc}
\hline & 2011 & 2012 \\
\hline Temperature $\left({ }^{\circ} \mathrm{C}\right)$ & $21.4 \pm 3.0$ & $20.8 \pm 2.9$ \\
Rainfall $(\mathrm{mm})$ & 23.4 & 30.6 \\
Relative humidity $(\%)$ & $33.0 \pm 12.5$ & $36.2 \pm 10.5$ \\
$\psi_{1}(\mathrm{MPa})$ & $-1.22 \pm 0.57$ & $-1.10 \pm 0.31$ \\
$\psi_{\mathrm{s}}(\mathrm{MPa})$ & -- & $-3.03 \pm 0.48$ \\
Groundwater table $(\mathrm{m})$ & $1.91-3.08$ & $1.63-2.65$ \\
\hline
\end{tabular}

Note: ${ }^{*}$ The growing season is defined as the period between a rapid increase and decrease in the sap flow of a branch of $T$. ramosissima (2011: 25 Apr to 23 Oct; 2012: 9 Apr to16 Oct); $\psi_{1}$ and $\psi_{\mathrm{s}}$ represent the average of leaf and soil water potential, respectively.

\subsection{HR and soil water depletion}

We calculated the HR of soil water by roots based on diurnal fluctuations in $\theta$ in each soil layer centered at depths of $10,30,50,80$, and $140 \mathrm{~cm}$ for two years. The measured $\theta$ declined during the day as roots extracted water from the soil, but at night or lower VPD $\theta$ increased in the upper soil layers as water moved into this layer via liquid and vapor transport or root hydraulic redistribution (Warren et al., 2011). However, as the soil dries the decline in soil unsaturated conductivity is indeed faster than the concurrent decrease in water potential, and therefore the liquid and vapor flux is known to approach zero (Siqueira et al., 2008) and the most of diurnal fluctuation in $\theta$ was root-mediated, i.e. HR (Domec et al., 2010). Net HR 
was defined as the nightly increase in $\theta$ and calculated as the difference between the minimum $\theta$ of one day and maximum $\theta$ of the next day. Water depletion (WD) of soil from each soil layer was calculated as the difference between daily maximum and minimum $\theta$ at each depth (Warren et al., 2011). HR and WD were not estimated on the day after a rainfall. Given that $\theta$ values at 80 and $140 \mathrm{~cm}$ were constantly increasing or decreasing during long-term measurement, HR values were only averaged at depths of 30 and $50 \mathrm{~cm}$. These values were then integrated across the profile to provide total daily $H R$ in the soil layer at depths of 20-60 cm. Daily WDs were integrated across depths to generate the daily total WD (TD; mm/d) of the upper 160 -cm soil layer.

\subsection{Data analysis}

Environmental data collected from the area, including $T_{a}$ and $\mathrm{RH}$, were used to calculate daytime $\left(R_{\mathrm{n}}>0\right)$ and nighttime $\left(R_{\mathrm{n}}<0\right)$ VPDs (expressed as VPD ${ }_{\mathrm{d}}$ and $\mathrm{VPD}_{\mathrm{n}}$, respectively) as well as VPD night:day ratios $\left(\mathrm{VPD}_{\mathrm{n} / \mathrm{d}}\right)$ in the upper canopy at a height of $3 \mathrm{~m}$. Combined with $R_{\mathrm{n}}$, these data provided the driving force for water movement in the soil-plant-atmosphere continuum (SPAC). We also calculated various soil water characteristics daily, including average upper $(30-\mathrm{cm})$ soil water content $\left(\theta_{u}\right), \mathrm{TD}$, and the ratio of upper to lower soil depletion (DR). $\theta_{u}$ reflects the spatial variation in micro-sites and the development of water potential gradients necessary to drive HR. TD corresponds to the root area and the strength of water extraction. DR corresponds to the root distribution in the context of root extraction strength and the development of water potential gradients. These data were used to explain spatial, seasonal, and annual variability exhibited in HR by standard ANOVA, correlation, and regression analysis in Origin 8 software (OriginLab Corp., Northampton, MA, USA). In stepwise regression analyses, additional parameters were only considered for inclusion if an improvement of $R^{2}>0.05$ was exhibited and if parameter estimates were significant.

\section{Results}

\subsection{Evidence of $\mathrm{HR}$}

Soil pits excavate and RLD calculations revealed a distinct, dense, fine-root layer at approximately 40$60 \mathrm{~cm}$ in the soil profile (Fig. 1). Soil cores also revealed that some larger diameter roots were established in the groundwater. The $\theta$ obtained from soil pits showed a distinctly higher value similar to RLD samples at a depth of $40 \mathrm{~cm}$ (Fig. 1), and it was significantly and negatively correlated to $\operatorname{RLD}\left(R^{2}=0.67\right)$. Long-term measurement of averagely seasonal variation in the leaf water potential of $T$. ramosissima showed that the leaf water potential was the greatest and the groundwater table was the lowest $(2.65 \mathrm{~m})$ in August, whereas the rainfall and temperature were relatively higher during the growing season (Fig. 2). Continuous recordings of average daily $\theta$ for two years showed that the $\theta$ was greater at $30 \mathrm{~cm}$ (mean of $\left.0.32 \mathrm{~cm}^{3} / \mathrm{cm}^{3}\right)$ and $50 \mathrm{~cm}\left(0.34 \mathrm{~cm}^{3} / \mathrm{cm}^{3}\right)$ than that at $10 \mathrm{~cm}\left(0.17 \mathrm{~cm}^{3} / \mathrm{cm}^{3}\right)$ and $80 \mathrm{~cm}\left(0.28 \mathrm{~cm}^{3} / \mathrm{cm}^{3}\right)$ during the growing season from May to October. The $\theta$ in the shallow soil layers $(10 \mathrm{~cm})$ was likely controlled by rainfall but did not affect soil moisture at depths of 30, 50, and $80 \mathrm{~cm}$ (Fig. 3).

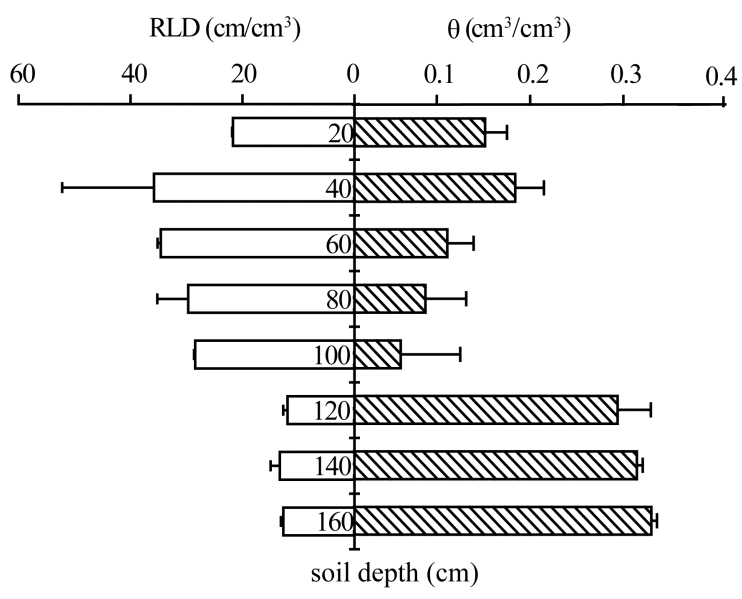

Fig. 1 Left: root length density (RLD, $\left.\mathrm{cm} / \mathrm{cm}^{3}\right)$ of $T$. ramosissima. Right: volumetric water content $\left(\theta, \mathrm{cm}^{3} / \mathrm{cm}^{3}\right)$ with respect to soil profile depths. Data are mean+S.E., $n=3$.

A pronounced diurnal fluctuation was observed in $\theta$ of $30 \mathrm{~cm}$ during midsummer in 2011 (Fig. 4a). The relationship between $\theta$ and corresponding $T_{\mathrm{s}}$ was not significant during a typically dry season (13 May to 18 September 2011), but the relationship was significant before and after these periods $\left(R^{2}\right.$ is 0.99 and 0.99 , respectively; Fig. 4b). A remarkable increase was observed at 10 and $140 \mathrm{~cm}$ after one rainfall event 

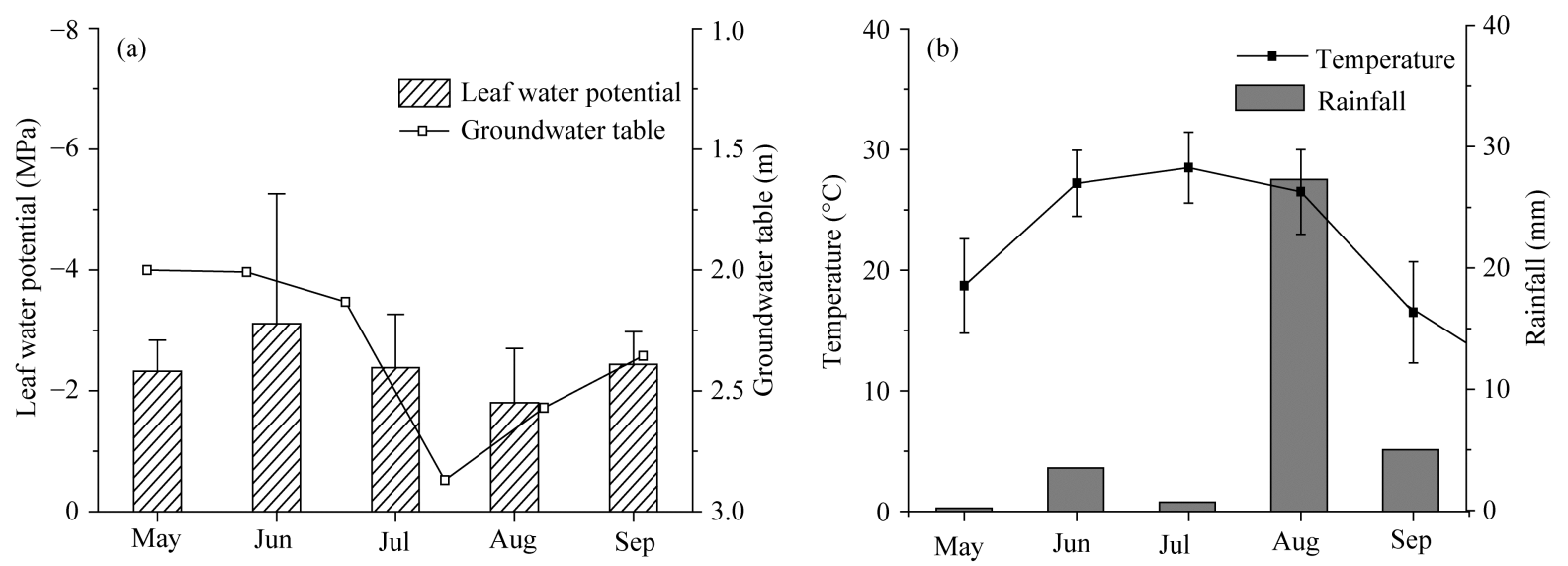

Fig. 2 Monthly variation in leaf water potential $(\mathrm{MPa})$ and groundwater table $(\mathrm{m})(\mathrm{a})$ and temperature $\left({ }^{\circ} \mathrm{C}\right)$ and rainfall $(\mathrm{mm})(\mathrm{b})$ for $T$. ramosissima during the growing season in 2011. Data are mean+S.E.

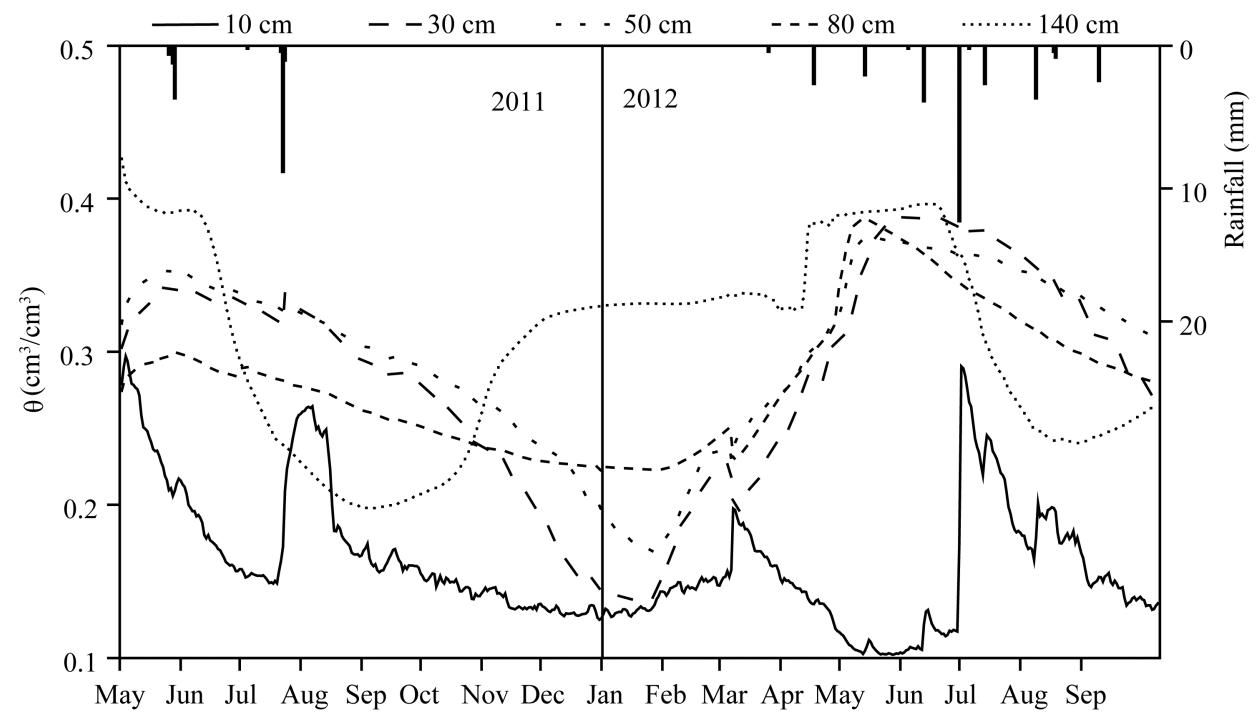

Fig. 3 Long-term recordings of soil volumetric water content $\left(\theta, \mathrm{cm}^{3} / \mathrm{cm}^{3}\right)$ at five different depths $(10,30,50,80$, and $140 \mathrm{~cm})$ in response to rainfall ( $\mathrm{mm}$, black bars) at $T$. ramosissima root zone. The higher values in the early days of 2011 and the sudden increase on 30 March, 2012 were induced by a new probe installation.
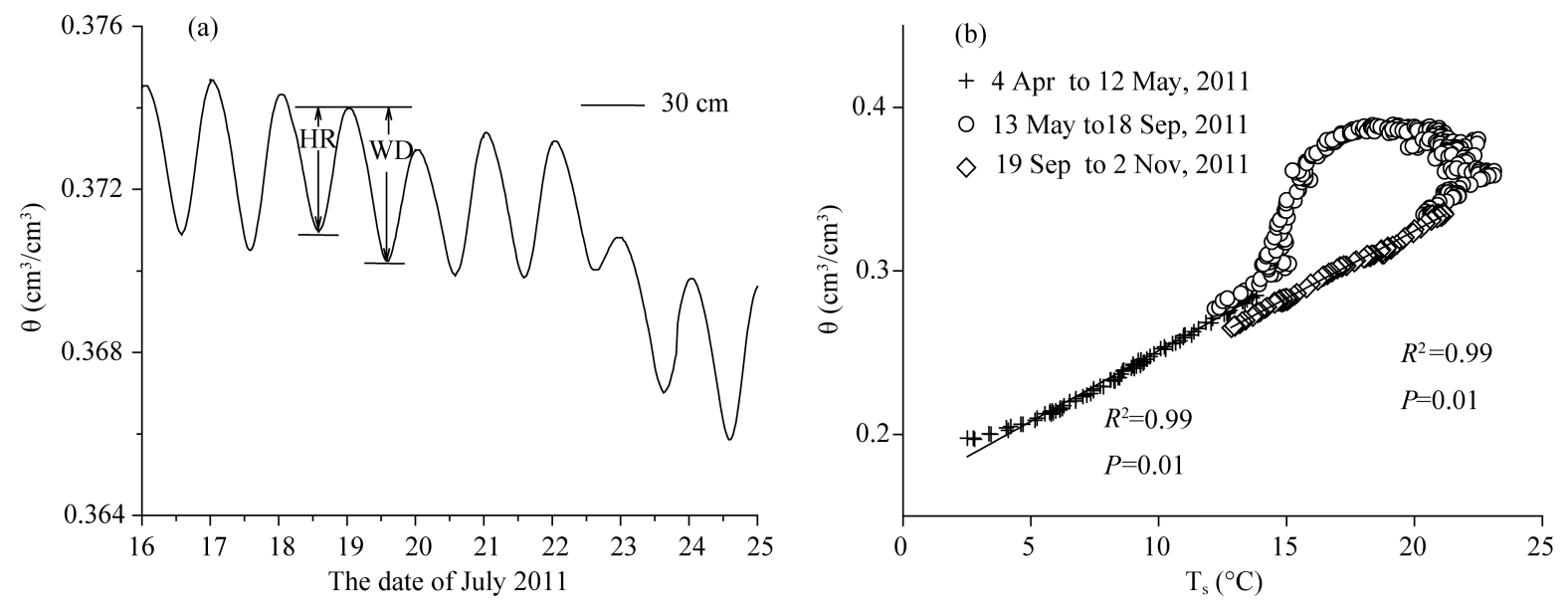

Fig. 4 Diurnal fluctuations of soil volumetric moisture content $\left(\theta, \mathrm{cm}^{3} / \mathrm{cm}^{3}\right)$ at $30 \mathrm{~cm}$ during midsummer (16 to 25 July 2011) (a), and the relationship between $\theta$ and corresponding soil temperature $\left(T_{\mathrm{s}},{ }^{\circ} \mathrm{C}\right)$ in root zone of $T$. ramosissima. Hydraulic redistribution and water depletion of soil are represented by HR and WD, respectively (b). 
(12.4 mm, 24 July 2012) but decreased at 30 and 50 $\mathrm{cm}$ and slightly changed at $80 \mathrm{~cm}$, indicating that the increase at $140 \mathrm{~cm}$ after rainfall was not caused by the infiltration of shallower soil water but was possibly transported by roots to deeper soil layers (Fig. 5a). The sap flow velocity in lateral roots was positive during day and night. However, the sap flow of branches showed a sharp reduction or even negatively

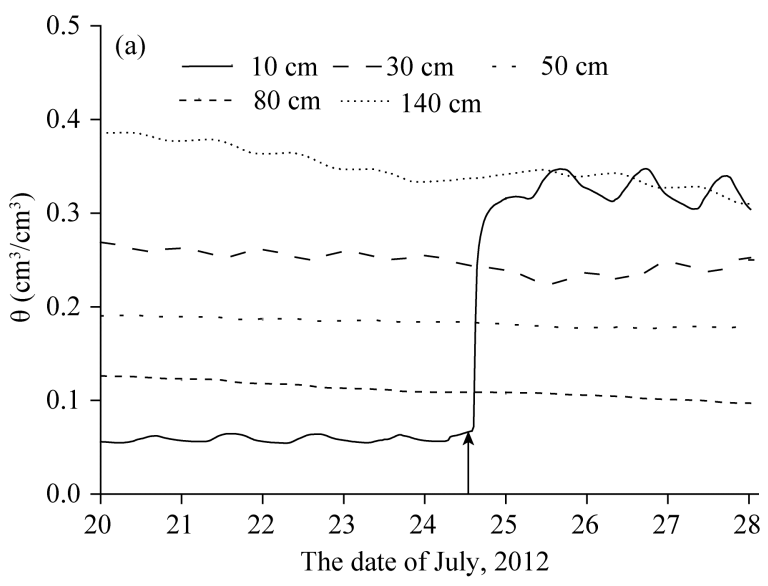

coincided with rainfall. Although the sap flow rates in lateral roots were still negative after rainfall, the sap flow at night after rainfall (25 to 28 July) was 1.77 and 2.57 times of the sap flow before the night (20 to 24 July) during the same period (Fig. 5b). This result strongly suggested that "hydraulic descent" (HD), in which the water absorbed by lateral roots, moved downward to deeper soil profiles via taproots.

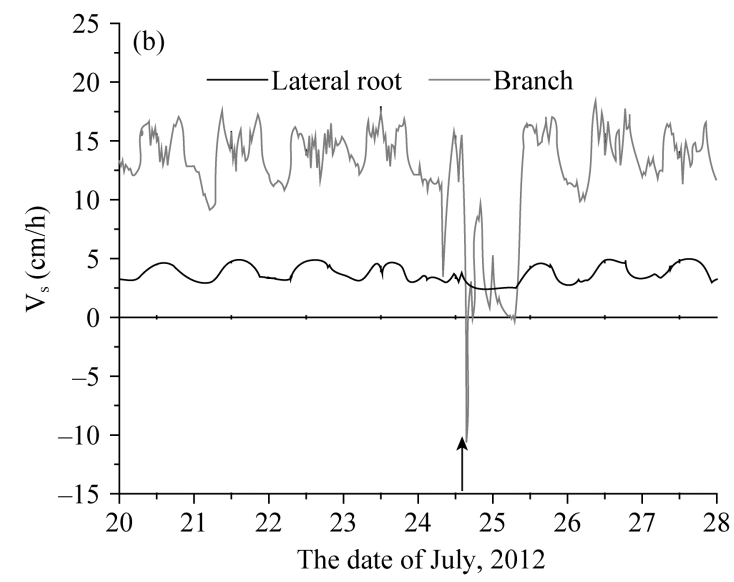

Fig. 5 Response of the soil volumetric moisture content $\left(\theta, \mathrm{cm}^{3} / \mathrm{cm}^{3}\right)$ in different soil layers (a) and the sap flow velocity $\left(V_{s}, \mathrm{~cm} / \mathrm{h}\right)$ of $T$. ramosissima branch and lateral roots to a rainfall $(12.4 \mathrm{~mm}$, vertical line with arrow) (b).

\subsection{Patterns of HR}

Large vertical variations in HR were found in the soil profile. In the area, the highest seasonal mean HR was found in the upper $10 \mathrm{~cm}$ of soil and then declined beneath this layer. However, WD was decreased at depths of more than $80 \mathrm{~cm}$ and increased farther beneath this layer (Fig. 6). Variations in HR at the upper $10 \mathrm{~cm}$ were negatively associated with WD of soil $\left(R^{2}=0.72\right)$ but were cancelled out by rainfall (Fig. 6a). $\mathrm{HR}$ of $30 \mathrm{~cm}$ was initiated on average during the previous two weeks before significant soil WD started and then peaked at $0.91 \mathrm{~mm} / \mathrm{d}$ on 31 May 2012 (severe drought with the lowest soil water content at the upper $10-\mathrm{cm}$ layer) with a mean of $0.27 \mathrm{~mm} / \mathrm{d}$ (Fig. $6 \mathrm{~b})$. The HR patterns of 50 and $80 \mathrm{~cm}$ were symmetrical to $\mathrm{WD}$, which was similar to that at $30 \mathrm{~cm}$ at the beginning but peaked at 0.43 and $0.34 \mathrm{~mm} / \mathrm{d}$ before $30 \mathrm{~cm}$ was reached with the mean values of 0.07 and $0.06 \mathrm{~mm} / \mathrm{d}$, respectively (Figs. $6 \mathrm{c}$ and d). HR and WD patterns at $140 \mathrm{~cm}$ were similar to those at 50 and $80 \mathrm{~cm}$ (Fig. 6e), and this finding was correlated with rainfall $\left(R^{2}=0.60, n=17\right)$, which may be attributed to HD. The HR pattern at depths of 20 to $60 \mathrm{~cm}$ was similar to that at $30 \mathrm{~cm}$ (Fig. 6f).

\subsection{Magnitude of $\mathrm{HR}$}

The seasonal pattern based on Penman-Monteith equation calculations of PET and soil water content estimates of TD (Fig. 7a) suggested that soil TD was negligible during winter and early spring. However, a pronounced lower TD that was consistent with the lower soil water content of surface soil layer (Fig. 3) was observed during summer, and then came to a sharp rise in the following rainfall event. By contrast, HR was greater during late spring and summer, indicating an average of $22 \%$ TD within the two years (Fig. 7b). In 2011, the monthly mean HR at 20-60 cm depths ranged between $0.88 \mathrm{~mm} / \mathrm{d}$ in May and 0.15 $\mathrm{mm} / \mathrm{d}$ in October, with an average of $0.47 \mathrm{~mm} / \mathrm{d}$. TD ranged from $4.27 \mathrm{~mm} / \mathrm{d}$ in June to $1.65 \mathrm{~mm} / \mathrm{d}$ in October, with an average of $3.11 \mathrm{~mm} / \mathrm{d}$ during the growing season. In 2012, HR ranged from $1.02 \mathrm{~mm} / \mathrm{d}$ in May to $0.14 \mathrm{~mm} / \mathrm{d}$ in October, with an average of 

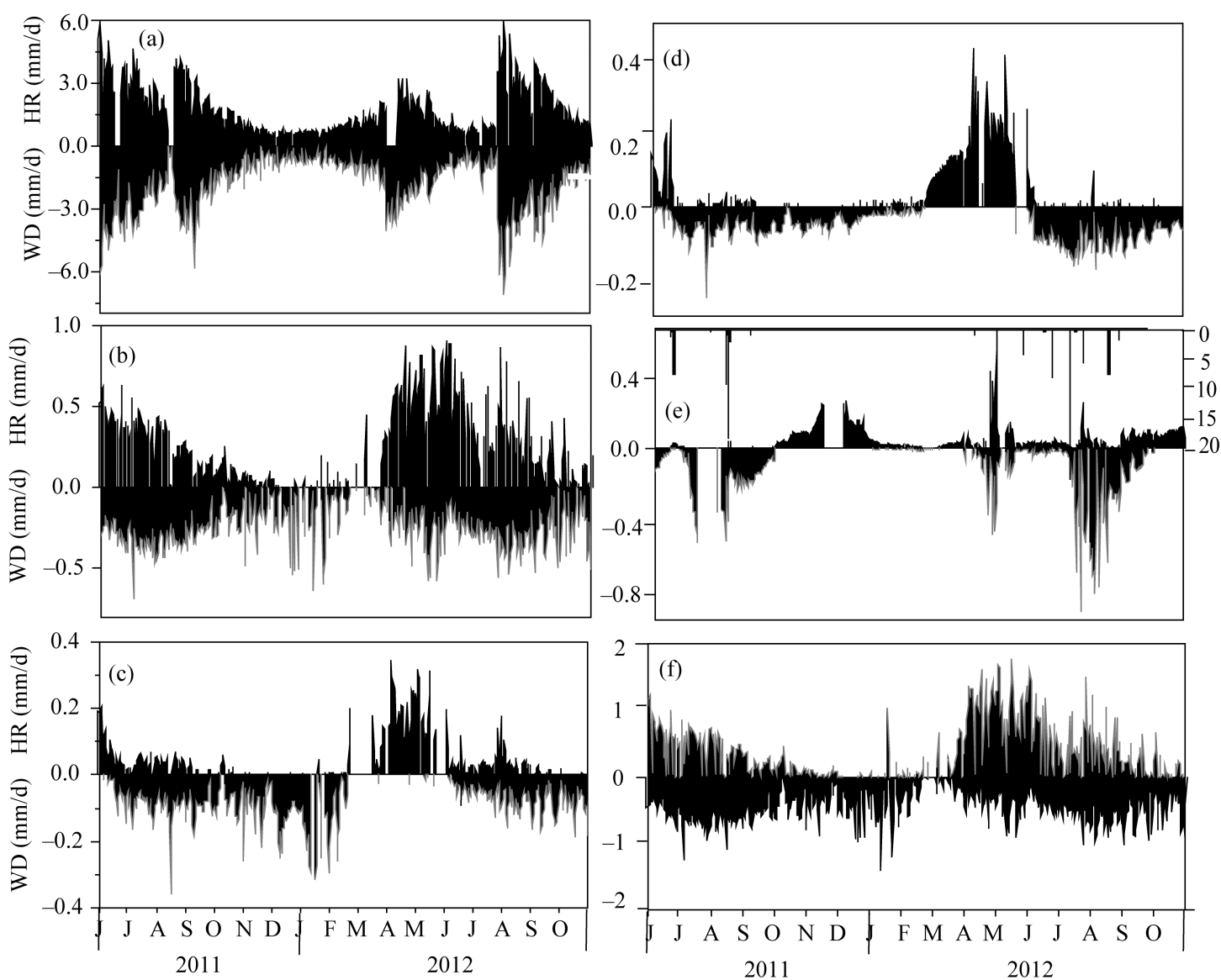

Fig. 6 Seasonal variation in hydraulic redistribution (HR; $\mathrm{mm} / \mathrm{d})$ of soil water by T. ramosissima roots and water depletion (WD; $\mathrm{mm} / \mathrm{d})$ at different depths: (a) $10 \mathrm{~cm}$, (b) $30 \mathrm{~cm}$, (c) $50 \mathrm{~cm}$, (d) $80 \mathrm{~cm}$, (e) $140 \mathrm{~cm}$, and (f) $20-60 \mathrm{~cm}$. The suspended bars in (e) represent rainfall $(\mathrm{mm})$.
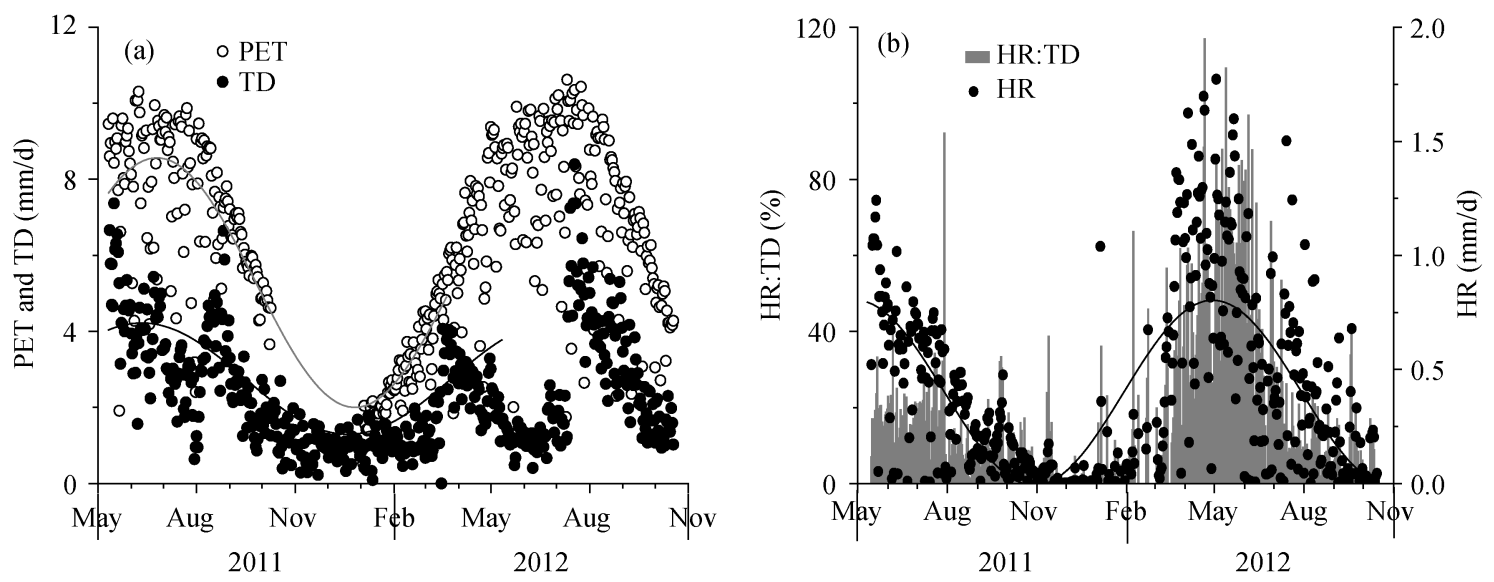

Fig. 7 Seasonal pattern (rainy days excluded) of the mean daily (a) potential evapotranspiration (PET; $\mathrm{mm} / \mathrm{d}$ ) and total water depletion (TD; $\mathrm{mm} / \mathrm{d}$ ) and (b) hydraulic redistribution (HR; $\mathrm{mm} / \mathrm{d}$ ) and the ratio of HR to TD (HR:TD, \%). Gray and black lines in (a) represent the seasonal fitted curves of PET $\left(R^{2}=0.64\right)$ and TD $\left(R^{2}=0.35\right)$, respectively. The black line in (b) represents the seasonal fitted curves of HR $\left(R^{2}=0.47\right)$.

$0.49 \mathrm{~mm} / \mathrm{d}$. However, TD reached a minimum of 1.55 $\mathrm{mm} / \mathrm{d}$ in June, with an average of $2.53 \mathrm{~mm} / \mathrm{d}$ during the growing season, which was far less than that in 2011 (Table 3). HR had an even greater effect on soil 
Table 3 Seasonal variations in daily mean hydraulic redistribution (HR; $\mathrm{mm} / \mathrm{d}$ ), total water depletion (TD; $\mathrm{mm} / \mathrm{d})$, and the ratio of $\mathrm{HR}$ to TD (HR/TD) of the growing season.

\begin{tabular}{ccccccccc}
\hline Year & & May & Jun & July & Aug & Sep & Oct & Average \\
\hline \multirow{4}{*}{2011} & PET (mm/d) & & $7.91 \pm 2.12$ & $8.21 \pm 1.69$ & $7.59 \pm 2.15$ & $6.81 \pm 0.69$ & $5.15 \pm 0.61$ & $7.37 \pm 1.43$ \\
& HR (mm/d) & & $0.67 \pm 0.33$ & $0.53 \pm 0.24$ & $0.40 \pm 0.21$ & $0.19 \pm 0.10$ & $0.15 \pm 0.11$ & $0.47 \pm 0.22$ \\
& TD (mm/d) & & $4.27 \pm 1.71$ & $3.45 \pm 1.11$ & $2.86 \pm 1.46$ & $3.34 \pm 1.24$ & $1.65 \pm 0.40$ & $3.11 \pm 1.10$ \\
& HR/TD & & 17.00 & 16.45 & 16.51 & 6.87 & 10.46 & 13.46 \\
& PET (mm/d) & $7.52 \pm 1.71$ & $8.05 \pm 1.75$ & $8.36 \pm 2.14$ & $8.18 \pm 1.87$ & $6.93 \pm 1.59$ & $5.01 \pm 1.11$ & $7.34 \pm 1.69$ \\
2012 & HR (mm/d) & $1.02 \pm 0.38$ & $0.74 \pm 0.45$ & $0.43 \pm 0.35$ & $0.44 \pm 0.30$ & $0.17 \pm 0.16$ & $0.14 \pm 0.16$ & $0.49 \pm 0.34$ \\
& TD (mm/d) & $1.99 \pm 0.57$ & $1.11 \pm 0.28$ & $2.40 \pm 1.28$ & $4.62 \pm 0.93$ & $3.35 \pm 1.03$ & $1.68 \pm 0.47$ & $2.53 \pm 1.16$ \\
& HR/TD & 51.15 & 53.33 & 22.55 & 10.12 & 6.58 & 8.76 & 25.42 \\
\hline
\end{tabular}

Note: PET, potential evapotranspiration; HR, hydraulic redistribution; TD, total water depletion; HR and TD are expressed as mean \pm S.E.

WD within $1.5 \mathrm{~m}$ and this effect changed seasonally. Early in the drought period (June), HR replaced a maximum of $53.33 \%$ of monthly mean TD from the soil layer, and reduced with increasing soil dryness, and even reached to $120 \%$ at some days. The monthly mean of the ratio of HR to TD in 2012 is twice as much as in 2011, which may attribute to the high soil water depletion at May and June with relatively shallow groundwater table (Fig. 2).

\subsection{Factors associated with HR}

Significant vertical and interannual variations were observed in the seasonal initiation and the total HR (Fig. 6). The statistical results revealed that climate and soil factors accounted for at least $33 \%$ and $45 \%$ of HR variation in depths and years, respectively (Table 4 ), influenced specifically by VPD, $T_{\mathrm{s}}$, TD, and DR. The related measured patterns of HR to VPD were weakened, whereas TD and $\theta$ were enhanced as the depth increased (Table 4a). The annual HR was positively correlated with VPD in the two years and soil
WD in the drier year $(23.4 \mathrm{~mm}, 2011)$, but this result was opposite to that exhibited in the wetter year (30.6 $\mathrm{mm}, 2012$; Table 2). Pearson correlation coefficient and stepwise regression performance were better in the drier year than in the wetter year (Table $4 b$ ).

\section{Discussion and conclusion}

Tamarix is a facultative but not an obligate phreatophyte. Similar to native riparian trees, Tamarix can transpire large quantities of water (Sala et al., 1996; Cleverly et al., 1997; Nagler et al., 2005). However, constant physiological function has been reported for Tamarix even during dry seasons in contrast to many co-occurring native phreatophytes (Cleverly et al., 1997; Devitt et al., 1997; Gries et al., 2003; Pataki et al., 2005). Tamarix can obtain multiple water sources and can possibly resist drought (Nippert et al., 2010). In this study area, the annual average precipitation is less than $40 \mathrm{~mm}$, whereas the potential evapotranspiration is greater than $3,000 \mathrm{~mm}$. Under high tempera-

Table 4 Statistical summary of the measured patterns of hydraulic redistribution (dependent variable) to environmental and climate parameters during the growing season of $T$. ramosissima stand

(a) Spatial variation in depths every year

\begin{tabular}{|c|c|c|c|c|c|c|c|c|c|c|}
\hline \multirow[b]{2}{*}{ Depth $(\mathrm{cm})$} & \multirow[b]{2}{*}{$n$} & \multicolumn{6}{|c|}{ Parameters significantly correlated with HR } & \multicolumn{3}{|c|}{ Regression analysis } \\
\hline & & $\mathrm{VPD}_{\mathrm{n}}$ & $\mathrm{VPD}_{\mathrm{d}}$ & DR & $\mathrm{T}_{\mathrm{s}}$ & TD & SWC & Model parameters & $F$ & $R_{\text {adj }}^{2}$ \\
\hline 30 & 169 & 0.45 & 0.41 & ns & -0.45 & -0.21 & -0.21 & VPDn, Ts, VPDd & 56 & 0.50 \\
\hline 40 & 168 & 0.38 & 0.36 & $\mathrm{~ns}$ & -0.47 & -0.22 & -0.26 & Ts, VPDd & 77 & 0.48 \\
\hline 50 & 150 & ns & ns & 0.42 & -0.45 & -0.26 & -0.30 & Ts, VPDd, DR & 25 & 0.33 \\
\hline
\end{tabular}

(b) Seasonal variation across depths within years

\begin{tabular}{|c|c|c|c|c|c|c|c|c|c|c|}
\hline \multirow[b]{2}{*}{ Year } & \multirow[b]{2}{*}{$n$} & \multicolumn{6}{|c|}{ Parameters significantly correlated to HR } & \multicolumn{3}{|c|}{ Regression analysis } \\
\hline & & $\mathrm{VPD}_{\mathrm{n}}$ & $\mathrm{VPD}_{\mathrm{d}}$ & DR & $\mathrm{T}_{\mathrm{s}}$ & TD & SWC & Model parameters & $F$ & $R_{\text {adj }}^{2}$ \\
\hline 2011 & 143 & 0.65 & 0.72 & ns & 0.33 & 0.63 & 0.61 & $\mathrm{VPD}_{\mathrm{d}}, \mathrm{TD}, \mathrm{T}_{\mathrm{s}}$ & 127 & 0.73 \\
\hline 2012 & 181 & 0.36 & 0.36 & 0.21 & -0.47 & -0.25 & -0.32 & $T_{\mathrm{s}}, \mathrm{VPD}_{\mathrm{d}}$ & 74 & 0.45 \\
\hline
\end{tabular}

Note: Model parameters include canopy vapor pressure deficit (VPD) during the day $\left(\mathrm{VPD}_{\mathrm{d}}\right)$ or night $\left(\mathrm{VPD}_{\mathrm{n}}\right)$, soil water content (SWC), total daily depletion (TD, 0-160 cm), the ratio of upper soil $(0-50 \mathrm{~cm})$ depletion to TD (DR), and soil temperature $\left(T_{\mathrm{s}}\right)$. Pearson correlation coefficient and stepwise regression were considered significant at $P<0.01$. Note that HR developed into three layers in (a) only in 2012. 
tures, the natural precipitation is depleted by evaporation before rainwater infiltrates into the deeper soil layers. Groundwater and soil water at depths of 20-60 $\mathrm{cm}$ are the main sources of water used by plants in the study area when runoff is unavailable during dry periods (Zhao et al., 2008). In the present study, the results showed that $T$. ramosissima could retain high $\theta$ at depths between 20 and $60 \mathrm{~cm}$ (Fig. 1) as well as a high leaf potential even at low groundwater table or high evaporation demand in dry periods (Fig. 2). Given the effect of rainfall on plant and soil, moisture balance is highly small in extremely arid regions $(\mathrm{Xu}$ and $\mathrm{Li}, 2006)$. Thus, the high $\theta$ at depths between 20 and $60 \mathrm{~cm}$ in dry periods could not be attributed to high rainfall; instead, groundwater uptake by plants could be possibly involved. However, groundwater uptake is possibly limited by the low densities of fine roots at deep soil layers under conditions of high evaporative demand given that the majority of fine roots ( $\leq 2 \mathrm{~mm}$ in diameter) of Tamarix is present near 40-60 cm (Fig. 1). Thus, high $\theta$ between 20 and $60 \mathrm{~cm}$ resulted from root systems absorbing deeper soil water and even groundwater, which are transported and released into the upper dry soil layer, i.e. "hydraulic lift" (HL) (Richards and Caldwell, 1987).

Although liquid and vapor transport of water through the soil without passing through the roots can significantly contribute to diurnal patterns of water flux (Warren et al., 2007), nocturnal increases in $\theta$ in the upper soil layer are often attributed to root water efflux, i.e. HR (Brooks et al., 2006). For example, the decrease in soil unsaturated conductivity is faster than the concurrent decrease in water potential as the soil dries; therefore, liquid water flux through soil approaches 0 (Siqueira et al., 2008). Prediction models have also shown that water fluxes associated with root HR are significantly greater than such fluxes associated with direct soil transport (Ryel et al., 2002). The relationship between $\theta$ and corresponding $T_{\mathrm{s}}$ is not significant during a typically dry season, suggesting that diurnal fluctuations of $\theta$ are root-mediated caused by $\mathrm{HR}$ and not liquid water transport induced by $T_{\mathrm{s}}$ fluctuation (Warren et al., 2011). Therefore, we attributed the nocturnal increases in $\theta$ to HR in this study. Adventitious roots and a clumped pattern of shal- low-rooted herbaceous plants around the crown of $T$. ramosissima were observed but absent in the clearing area, suggested that coexisting plant species mainly absorb hydraulically lifted water released by adventitious roots of $T$. ramosissima to ensure survival, i.e. water parasitism (Richards and Caldwell, 1987; Dawson, 1993). However, the sap flow measurements of lateral roots did not provide direct evidence supporting HL of T. ramosissima (Fig. 5a). These results indicated that the HR pathway is not found in lateral roots, but in adventitious roots, with a diameter of $2-5 \mathrm{~mm}$ and length of $60-100 \mathrm{~cm}$ between depths of 40 and $60 \mathrm{~cm}$.

The seasonally variation of TD suggested that soil water depletion can be negligible during winter but pronounced lower during summer (Fig. 7a), being consistent with the lower soil water content of surface soil layer (Fig. 3), and then came to a sharp rise in the following rainfall event (Fig. 7a). Daily mean HR at depths of $20-60 \mathrm{~cm}$ ranged from $0.01-1.77 \mathrm{~mm} / \mathrm{d}$, with a mean HR of $0.43 \mathrm{~mm} / \mathrm{d}$. Thus, the effect of HL on plant water use is important, in which a stable $\theta$ is retained to satisfy high evaporation demands during dry season (Figs. 3 and 5a). This result is similar to the empirical range from 0.04 to $1.3 \mathrm{~mm} / \mathrm{d}$ but significantly less than the simulative range from 0.1 to $3.23 \mathrm{~mm} / \mathrm{d}$ (Neumann and Cardon, 2012). The fraction of total daily WD from the upper $160-\mathrm{cm}$ soil layer was replaced by HR in the upper soil layer; HL was increased during extremely drought periods, with an average of $22 \%$ (Fig. $7 \mathrm{~b}$ ), and even reached to $120 \%$ during the dry season. The possible reasons for this difference is that roots can absorb water directly from groundwater, and this finding was also noted in strong HL of East African umbrella thorn (Ludwig et al., 2003) and oak in southern Portugal (Kurz-Besson et al., 2006).

In addition to HL, HD is another main facet of HR. In $T$. ramosissima branches, the sap flow velocity is negative and decreases in one of the lateral roots when the surface soil is wetted by rainfall, suggesting that water uptake from the upper soil profile contributes greatly to plant water consumption given that the plants depend mainly on deep roots to obtain water supply during drought (Fig. 5a). It was also observed 
that an evident increase was at the depths of 10 and $140 \mathrm{~cm}$; and instead, a decrease was at 30 and $50 \mathrm{~cm}$ a slight change was at $80 \mathrm{~cm}$ (Fig. 5b). These results indicated that rainfall was absorbed by adventitious roots and transferred downward by taproots to drier, deeper soil layers. The magnitude of daily mean HD ranged from $0.002-0.43 \mathrm{~mm} / \mathrm{d}$, with a mean of $0.07 \mathrm{~mm} / \mathrm{d}$ (Fig. 6e). Although HD is less than HL, the effect of HD on soil moisture balance should not be ignored. During rainy days, the transpiration demand of plants can be low (Fig. 7a), resulting in less effective competition between atmosphere and dry soil for water within the plant, which enables daytime HD (Fig. 5a) and increases the deep soil water content (Fig. 5b) and TD (Fig. 6b). These effects likely prolonged root functionality and enabled low seasonal leaf water potential during the wet season (Prieto et al., 2012).

The increase of $\theta$ at the depth of $140 \mathrm{~cm}$ after a rainfall event can be ascribed to the lateral flow of water and capillary rise from the groundwater table, and also the proximity of the river would explain it. However, the channel was dry in July, which implies that the soil water recharge by groundwater is limited by lower burial depth ( $2.41 \mathrm{~m}$ on 25 July), even capillary rise cannot extend to $80 \mathrm{~cm}$ above the groundwater table based on experience estimation using 0.73 divided by soil particle radius with mean of $0.01 \mathrm{~cm}$ (Zhou et al., 2004). Thus, the increase of $\theta$ at depth of $140 \mathrm{~cm}$ after a rainfall event is induced by the HR rather than the lateral flow of water and capillary rise. These results also suggested that $T$. ramosissima is a highly opportunistic water user that can effectively use soil water wherever available.

Significant vertical and interannual variations were observed in the seasonal initiation and magnitude of HR (Fig. 6). The regression analysis demonstrated that climate and soil WD accounted for at least $33 \%$ and $45 \%$ of HR variation in depths and years, respectively (Table 4), specifically driven by VPD, $T_{\mathrm{s}}$, TD, and DR. VPD is the main driving force of HR (Warren et al., 2007), and this factor regulates water demand to increase soil WD and is associated with HR. TD, DR, and $T_{\mathrm{s}}$ influence HR and its pattern by reducing soil water potential or temperature gradient. The effect of $T_{\mathrm{s}}$ on HR is consistent (Table 4) as indicated by $\theta$ (Fig.
$4 \mathrm{~b})$. Warren et al. (2011) suggested that $T_{\mathrm{s}}$ fluctuations can also drive nighttime soil vapor transport, accounting for a maximum of $40 \%$ of the nocturnal increase in upper soil layers; thus, the effect of $T_{\mathrm{s}}$ on HR should be considered in an HR model.

In summary, our results suggested that HR (including HL and HD) occurs in T. ramosissima. However, the HR pathway is not via the lateral roots as we measured, which did not provide direct evidence supporting HR of T. ramosissima; instead, HR occurs via adventitious roots with a diameter of $2-5 \mathrm{~mm}$ and a length of $60-100 \mathrm{~cm}$. The large amount of redistributed water may correspond to a considerable fraction of daily soil WD and substantially improved plant water status. The climate factors, specifically VPD and soil water potential or temperature gradient, accounted for at least $33 \%$ and $45 \%$ of HR variation with soil depths and years, respectively.

\section{Acknowledgments}

This study was supported by the Key Project of the Chinese Academy of Sciences (KZZD-EW-04-05), the National Natural Science Foundation of China (91025024), and the Western Light Project of the Chinese Academy of Sciences.

\section{References}

Allen R G, Pereira L S, Raes D, et al. 1998. Crop evapotranspirationguidelines for computing crop water requirements-FAO Irrigation and Drainage Paper 56, FAO, Rome, Italy.

Anderson J E. 1982. Factors controlling transpiration and photosynthesis in Tamarax Chinensis Lour. Ecology, 63: 48-56.

Brooks J R, Meinzer F C, Warren J M, et al. 2006. Hydraulic redistribution in a Douglas-fir forest: lessons from system manipulations. Plant, Cell \& Environment, 29: 138-150.

Burgess S S O, Adams M A, Turner N C, et al. 1998. The redistribution of soil water by tree root systems. Oecologia, 115: 306-311.

Burgess S S O, Pate J S, Adams M A, et al. 2000. Seasonal water acquisition and redistribution in the Australian woody phreatophyte, Banksia prionotes. Annals of Botany, 85: 215-224.

Burgess S S O, Adams M A, Turner N C, et al. 2001. An improved heat pulse method to measure low and reverse rates of sap flow in woody plants. Tree Physiology, 21: 589-598.

Busch D E, Ingraham N L, Smith S D. 1992. Water uptake in woody riparian phreatophytes of the southwestern United States: a stable isotope study. Ecological Applications, 2: 450-459.

Caldwell M M, Richards J H. 1989. Hydraulic lift: water efflux from 
upper roots improves effectiveness of water uptake by deep roots. Oecologia, 79: 1-5.

Cleverly J R, Smith S D, Sala A, et al. 1997. Invasive capacity of Tamarix ramosissima in a Mojave Desert floodplain-the role of drought. Oecologia, 111: 12-18.

Dawson T E. 1993. Hydraulic lift and water use by plants-implications for water balance, performance and plant-plant interactions. Oecologia, 95: 565-574.

Devitt D A, Smith S D, Neuman D S. 1997. Leaf carbon isotope ratios in three landscape species growing in an arid environment. Journal of Arid Environments, 36: 249-257.

Domec J C, King J S, Noormets A, et al. 2010. Hydraulic redistribution of soil water by roots affects whole-stand evapotranspiration and net ecosystem carbon exchange. New Phytologist, 187: 171-183.

Feng Q, Cheng G D. 1998. Current situation, problems and rational utilization of water resources in arid north-western China. Journal of Arid Environments, 40: 373-382.

Gries D, Zeng F J, Foetzki A, et al. 2003. Growth and water relations of Tamarix ramosissima and Populus euphratica on Taklamakan desert dunes in relation to depth to a permanent water table. Plant, Cell \& Environment, 26: 725-736.

Hultine K R, Williams D G, Burgess S S O, et al. 2003. Contrasting patterns of hydraulic redistribution in three desert phreatophytes. Oecologia, 135: 167-175.

Hultine K R, Scott R L, Cable W L, et al. 2004. Hydraulic redistribution by a dominant, warm-desert phreatophyte: seasonal patterns and response to rainfall pulses. Functional Ecology, 18: 530-538.

Jackson R B, Canadell J, Ehleringer J R, et al. 1996. A global analysis of root distributions for terrestrial biomes. Oecologia, 108: 389-411.

Jackson R B, Mooney H A, Schulze E D. 1997. A global budget for fine root biomass, surface area, and nutrient contents. Proceedings of the National Academy of Sciences, 94: 7362-7366.

Kurz-Besson C, Otieno D, Lobo do Vale R, et al. 2006. Hydraulic lift in cork oak trees in a Savannah-type Mediterranean ecosystem and its contribution to the local water balance. Plant and Soil, 282: 361-378.

Lambers H, Chapin III F S, Pons T L. 2008. Plant water relations. In: Lambers H, Chapin III F S, Pons T L. Plant Physiological Ecology. New York: Springer Science+Business Media, 163-217.

Liu C, Chen Y N, Xu Z. 2010. Eco-hydrology and sustainable development in the arid regions of China. Hydrological Processes, 24: $127-128$.

Ludwig F, Dawson T E, Kroon H, et al. 2003. Hydraulic lift in Acacia tortilis trees on an East African savanna. Oecologia, 134: 293-300.

Nagler P, Scott R, Westenburg C, et al. 2005. Evapotranspiration on western U.S. rivers estimated using the Enhanced Vegetation Index from MODIS and data from eddy covariance and Bowen ratio flux towers. Remote Sensing of Environment, 97: 337-351.

Nagler P L, Glenn E P, Lewis T T. 2003. Comparison of transpiration rates among saltcedar, cottonwood and willow trees by sap flow and canopy temperature methods. Agricultural and Forest Meteorology,
116: 73-89.

Neumann R B, Cardon Z G. 2012. The magnitude of hydraulic redistribution by plant roots: a review and synthesis of empirical and modeling studies. New Phytologist, 194: 337-352.

Nippert J B, Butler J J, Kluitenberg G J, et al. 2010. Patterns of Tamarix water use during a record drought. Oecologia, 162: 283-292.

Oliveira R S, Dawson T E, Burgess S S O. 2005. Evidence for direct water absorption by the shoot of the desiccation-tolerant plant Vellozia flavicans in the savannas of central Brazil. Journal of Tropical Ecology, 21: 585-588.

Pataki D E, Bush S E, Gardner P, et al. 2005. Ecohydrology in a Colorado River riparian forest: implications for the decline of Populus fremontii. Ecological Applications, 15: 1009-1018.

Prieto I, Armas C, Pugnaire F I. 2012. Hydraulic lift promotes selective root foraging in nutrient-rich soil patches. Functional Plant Biology, 39: 804-812.

Richards J H, Caldwell M M. 1987. Hydraulic lift: substantial nocturnal water transport between soil layers by Artemisia tridentata roots. Oecologia, 73: 486-489.

Ryel R J, Caldwell M M, Yoder C K, et al. 2002. Hydraulic redistribution in a stand of Artemisia tridentata: evaluation of benefits to transpiration assessed with a simulation model. Oecologia, 130: 174-183.

Sala A, Smith S D, Devitt D A. 1996. Water use by Tamarix ramosissima and associated phreatophytes in a Mojave desert floodplain. Ecological Applications, 6: 888-898.

Si J H, Feng Q, Zhang Y W, et al. 2005. Growing season evapotranspiration from Tamarix ramosissima stands under extreme arid conditions in northwest China. Environmental Geology, 48: 861-870.

Siqueira M, Katul G G, Porporato A. 2008. Onset of water stress, hysteresis in plant conductance, and hydraulic lift: scaling soil water dynamics from millimeters to meters. Water Resources Research, 44: W01432.

Warren J M, Meinzer F C, Brooks J R, et al. 2007. Hydraulic redistribution of soil water in two old-growth coniferous forests: quantifying patterns and controls. New Phytologist, 173: 753-765.

Warren J M, Brooks J R, Dragila M I, et al. 2011. In situ separation of root hydraulic redistribution of soil water from liquid and vapor transport. Oecologia, 166: 899-911.

Xi H Y, Feng Q, Si J H, et al. 2011. Spatio-temporal characteristics of soil in Ejina oasis. Journal of Desert Research, 31: 68-75.

$\mathrm{Xu} \mathrm{H}$, Li Y. 2006. Water-use strategy of three central Asian desert shrubs and their responses to rain pulse events. Plant and Soil, 285: 5-17.

Zhao L J, Xiao H L, Cheng G D, et al. 2008. A preliminary study of water sources of riparian plants in the lower reaches of the Heihe basin. Acta Geoscientica Sinica, 29: 709-718.

Zhou X, Fang B, Cao W B, et al. 2004. Occurrence of water and salts in the unsaturated zone in the Ejin oasis in Northwest China. Geological Review, 50: 384-390. 